\title{
Implementation of different 2D finite element modelling approaches in axial flux permanent magnet disc machines
}

ISSN 1751-8660

Received on 26th July 2017

Revised 17th September 2017

Accepted on 30th September 2017 E-First on 8th November 2017 doi: 10.1049/iet-epa.2017.0434 www.ietdl.org

\author{
Mehmet Gulec ${ }^{1}$, Metin Aydin ${ }^{1}$ \\ ${ }^{1}$ Department of Mechatronics Engineering, Kocaeli University, Eski Istanbul Yolu 10. km, Kocaeli 41380, Turkey \\ 凶E-mail:mehmet.gulec@kocaeli.edu.tr
}

\begin{abstract}
Three-dimensional (3D) finite element (FE) modelling of axial flux permanent magnet (AFPM) motors is one of the time-consuming tasks which must be completed before manufacturing the prototype motor. A simple, fast, accurate, and effective numerical modelling approach for such 3D problems would be particularly useful for researchers. This study presents simple and effective 2D FE modelling approaches for AFPM motors with good accuracy with less computational effort. The modelling approaches are based on a number of 2D models or planes with inner rotor, outer rotor, or linear motor topologies. All the 2D planes with either topology are superposed together to represent the real AFPM machine. These approaches are examined in detail with various types of experimentally verified AFPM motors. Results obtained from the proposed modelling approaches are verified with 3D FE analyses and experimental data. The results indicate that the proposed 2D modelling approaches can significantly reduce the computation time with good accuracy as opposed to conventional 3D FE modelling of AFPM motors.
\end{abstract}

\section{Introduction}

The use of permanent magnet (PM) synchronous motors has widely increased after the developments of permanent magnets and motor drives in early 1980 s. Since then, researchers focused on various PM motor designs with more efficiency, and torque density. Axial flux permanent magnet (AFPM) motors are increasingly used in various applications due to their high power density, high efficiency, compact structures, and geometric advantages. They allow designers to create unique topologies with multiple stators and rotors. Therefore, such motors have great potentials in various special applications with low and high pole numbers such as traction, appliance, and defence [1-4].

Finite element analysis (FEA) is a critical tool in today's world in the design of conventional and unconventional PM motors. It is used in the analysis, design, and optimisation of electric motors before prototyping or mass production. Development of the available FEA packages has allowed engineers to design PM motors more accurately and rapidly [5-8].

Axial flux machines (AFM) are three-dimensional (3D) problems because of the 3D flux distribution unlike most conventional radial flux machines. Therefore, 3D FE models are required for accurate computations. However, modelling such complex geometry takes significant amount of time compared with 2D FEA modelling and requires serious competency [9-12]. Although 3D FEA modelling is the most used technique in the literature in modelling AFPM motors, most engineers do not wish to generate 3D FEA models because of the modelling difficulty and time wasted to obtain reasonable results. In order to evaluate the AFPM machine performance accurately with less effort and more ease, 2D FEA modelling approach would be very interesting for researchers and designers.

Two-dimensional FEA modelling of AFPM motors can be realised in several manners. Modelling AFPM motors with several 2D linear motors, which can also be called 'linear motor modelling approach (LMMA)', is the only approach used in the literature [13-20]. The 2D FE modelling with LMMA is not investigated thoroughly for such AFPM motors. While some researchers used for only one LMMA at the average radius, some studies are focused on multiple 2D linear models at different radii in the circumferential direction of the stator discs. However, it has to be noted that no-load performance of the AFPM disk motors are examined with the LMMA. Furthermore, 2D modelling of AFPM motors with inner or outer rotor modelling approaches for AFPM motors is not investigated earlier in the literature. Two-dimensional inner or outer rotor modelling approaches can be completed in no time unlike LMMA thanks to FE software tools. In addition, some of AFPM motor topologies with slotted and non-slotted stator cores could provide more accurate results as opposed to LMMA and it is worth investigating.

In this paper, it is shown how 3D AFPM motor models can be converted into $2 \mathrm{D}$ radial flux motor models with inner and outer rotors and 2D linear motor models for several 2D cut planes. Although 2D LMMA is covered in the literature before, this paper covers both no-load and on-load performances of previously built AFPM motors with several 2D LMMA. In addition, several 2D inner rotor modelling approach (IRMA) and outer rotor modelling approach (ORMA) for AFPM motors are investigated for the first time in the literature due to the benefits they may provide. Superposition of the results are compared with 3D FEA as well as several previously built AFPM motor data to illustrate the feasibility of the 2D modelling approaches presented.

The paper is structured as follows: design strategy and fundamental equations for AFPM machines are briefly described in the first section. Steps of reducing 3D motor models into 2D models are clarified in the following section in detail. The approaches proposed in the paper are applied to various previously built and verified AFPM motors and the feasibility of the proposed 2D modelling approaches are presented. Comparison among the proposed 2D FEA approaches, 3D FEA, and experimental data are also provided for the tested AFPM motors. Comparison of 3D FEA and 2D FEA approaches based on computational time is also presented. Final suggestions about which approach could be used based on AFPM motor topology are provided for the motor designers in the last section of the paper.

\section{Design and modelling of AFPM motors}

The AFPM motors have several configurations as displayed in Fig. 1. The motors could have one stator and one rotor as well as multiple stators and multiple rotors. The stator might have strip wound core with or without slots. The winding structures could have a variety of options from distributed to concentrated 


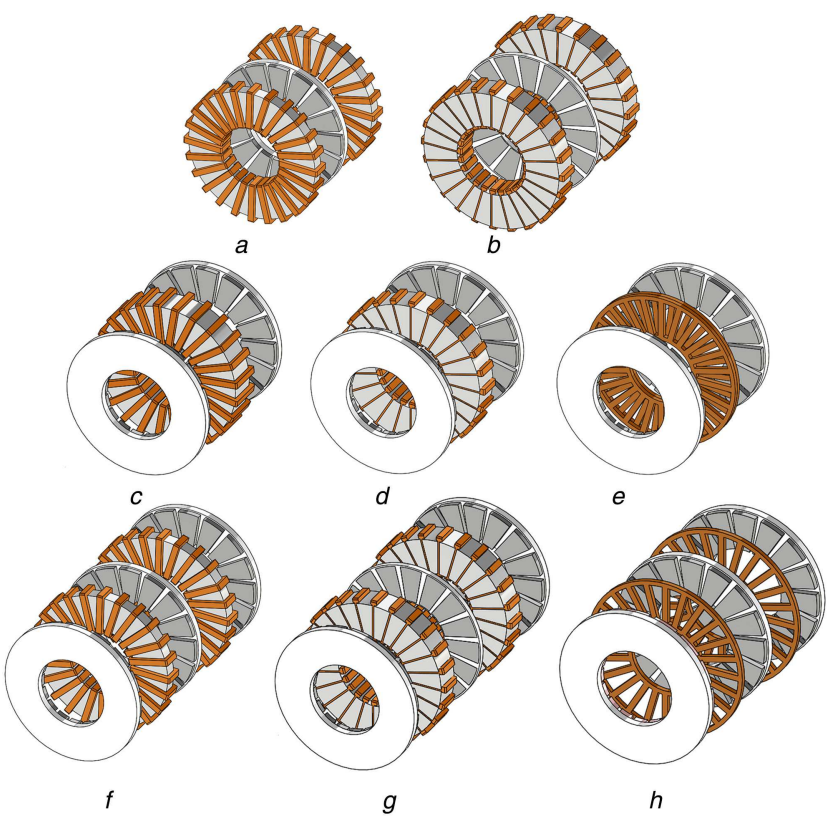

Fig. 1 AFPM synchronous motor topologies

$(\boldsymbol{a}, \boldsymbol{b})$ Dual stator-single rotor, $(\boldsymbol{c}-\boldsymbol{e})$ Dual rotor-single stator, $(\boldsymbol{f}-\boldsymbol{h})$ Multiple statormultiple rotor

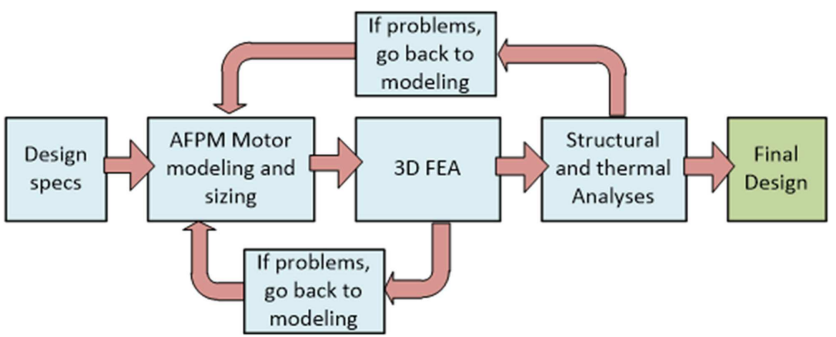

Fig. 2 Design procedure for AFPM motors with 3D FEA incorporated

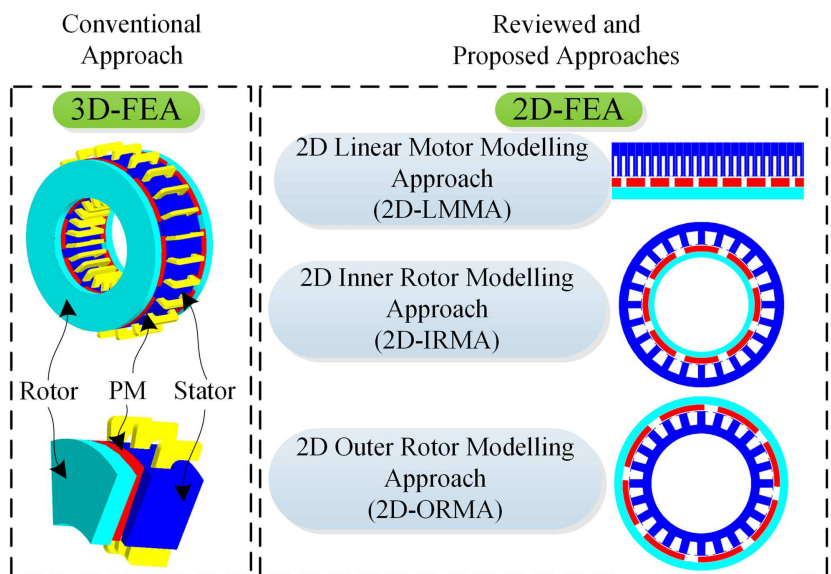

Fig. 3 FEA modelling approaches of AFPM motors with $3 D$ FEA, reviewed and proposed $2 D$ FEA

windings. NdFeB magnets are usually preferred due to their high flux capability.

Iterative design procedure for any AFPM motor for special applications includes electromagnetic, structural, and thermal designs as displayed in Fig. 2. Electromagnetic design comprises magnetic circuit-based models with motor sizing. After finding a design that meets specifications, motor structure has to be modelled in 3D FEA to verify the actual motor performance. Then, the design can be finalised after structural and thermal checks.

The design of AFPM motors can be accomplished using sizing analysis approach which is described in earlier studies [3, 4, 21]. The sizing equations for a three-phase AFPM machine have the following form:

$$
P_{\mathrm{R}}=K_{A} \eta B_{\mathrm{g}} A \frac{f}{p}\left(1-\lambda^{2}\right) \frac{1+\lambda}{2} D_{\mathrm{o}}^{2} L_{\mathrm{e}}
$$

where $P_{\mathrm{R}}$ is the rated output power of the machine, $L_{\mathrm{e}}$ the effective stack length of the machine, $f$ the frequency, $p$ the pole pair, $B_{\mathrm{g}}$ the air gap flux density, $\eta$ the motor efficiency, $K_{A}$ the waveform constant, and $\lambda$ the diameter ratio of the AFPM machine which is defined as

$$
\lambda=\frac{D_{\mathrm{i}}}{D_{\mathrm{o}}}
$$

where $D_{\mathrm{o}}$ and $D_{\mathrm{i}}$ are machine diameters at outer and inner surfaces. This parameter is the most important design parameter of AFPM machines.

The back-EMF is given by

$$
e(t)=k_{\mathrm{w}} N B_{\mathrm{g}} \frac{f}{p} D_{\mathrm{g}} L_{\mathrm{e}} f_{\mathrm{e}}(t)
$$

The peak value of the phase back-EMF is given by

$$
E_{\mathrm{PK}}=k_{\mathrm{wk}} N B_{\mathrm{g}} \frac{f}{p} D_{\mathrm{g}} L_{\mathrm{e}}
$$

where $k_{\mathrm{wk}}$ is the $k$ th winding factors, $N$ the number of turns, and $D_{\mathrm{g}}$ the diameter of the machine air gap. Then, the torque density equation becomes

$$
T_{\mathrm{den}} \simeq \frac{4}{\pi} \frac{1}{\omega_{m}} K_{A} \eta B_{\mathrm{g}} A \frac{f}{p}\left(1-\lambda^{2}\right) \frac{1+\lambda}{2}
$$

Initial motor sizing can be obtained using the above equations based on the specifications and then 2D/3D FEA simulations can be completed.

\section{Finite element modelling approaches for AFPM disc motors}

In general, standard RFPM motors are usually 2D problems and can be modelled using 2D FEA. However, AFPM motors have 3D flux paths and have to be modelled using 3D FEA. Therefore, accurate modelling of AFPM motors is vital to get accurate output parameters. Nevertheless, modelling with 3D FEA and running all the required simulations take significant amount of computation time compared with conventional 2D motor problems. In addition, computation or solution time depends on the complexity of the problem, including motor sizing, motor topology such as cored or coreless, pole numbers, number of stators, slot shapes, and applied frequency of the source as well as rotor topology. Therefore, a simple, fast, and efficient 2D modelling would be useful for motor designers.

FEA modelling of AFPM motors can be categorised into two main groups: 2D/3D modelling approaches (Fig. 3). Threedimensional FEA modelling is the most used technique in the literature in modelling AFPM motors. Two-dimensional FEA modelling with LMMA is investigated for AFPM motors before limited to no-load simulations. Furthermore, 2D modelling with IRMA or ORMA for AFPM motors are not investigated earlier.

Investigated approaches, which are called IRMA, PRMA, and LMMA, lie on slicing a 3D AFPM motor problem into a number of 2D problems considering the topology and motor symmetry. Schematic of this conversion process is displayed in Fig. 4 for a slotted dual-rotor AFPM motor. First, the motor symmetry model is found and set aside. Each symmetric 3D problem is then sliced into 3D symmetry models. This 3D symmetric model is approximated to several numbers of '2D motor models' at different radii. In other words, each 2D approximated model represents different radial cross-section of the AFPM motor. Contrary to 2D LMMA, 2D IRMA and 2D ORMA motor models would have various innerouter diameter according to radius of cut-planes. The inner-outer diameters are determined by the radius of the air-gap for each $2 \mathrm{D}$ 


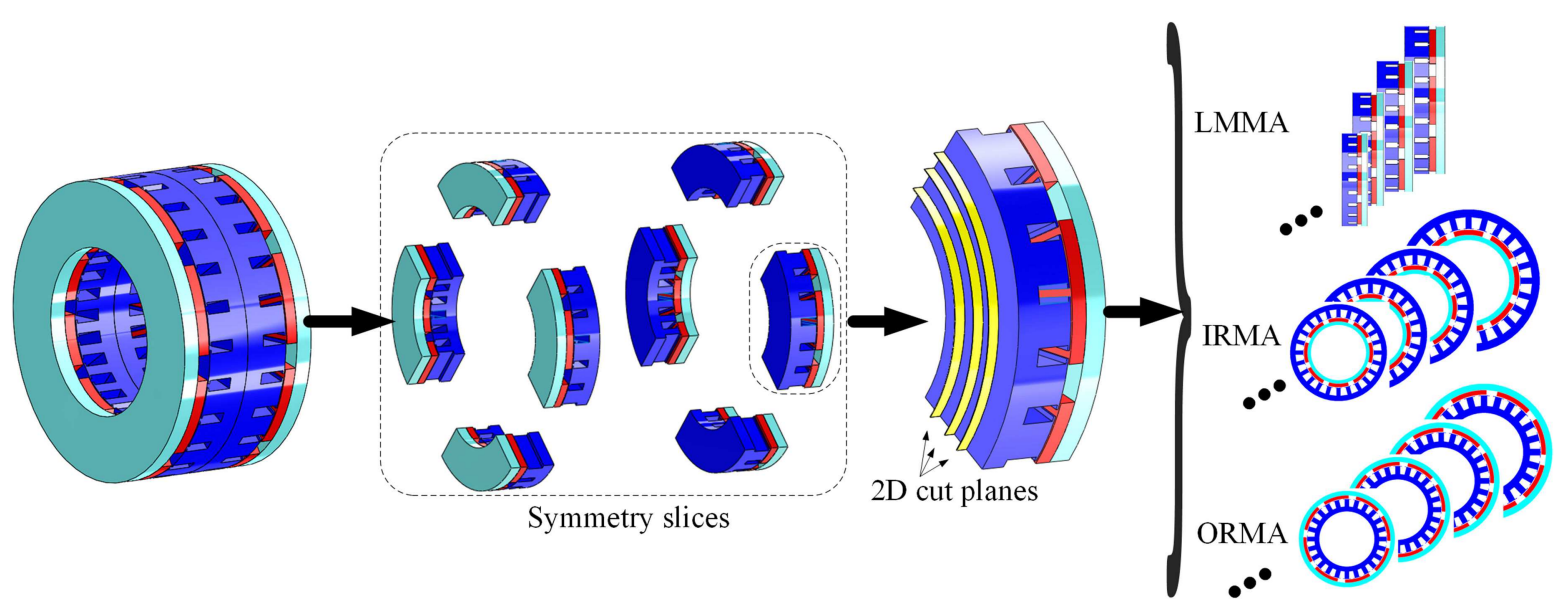

Fig. 4 Reduction in 3D AFPM motor problems to 2D AFPM motor problems by using $2 D$ symmetry modelling approach for a double rotor-single stator axial flux PM motor

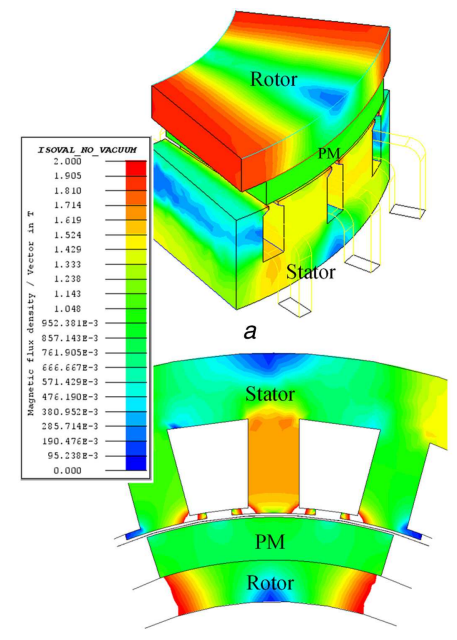

c

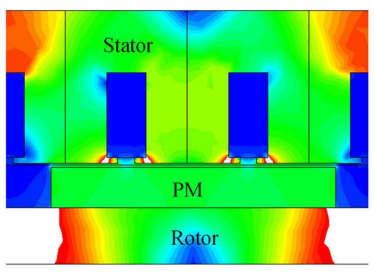

$b$

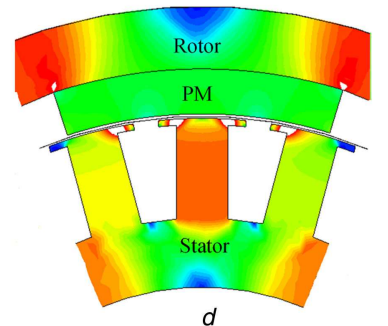

$d$

Fig. 5 Flux density profile of

(a) 3D FEA, (b) 2D LMMA, (c) 2D IRMA, (d) 2D ORMA
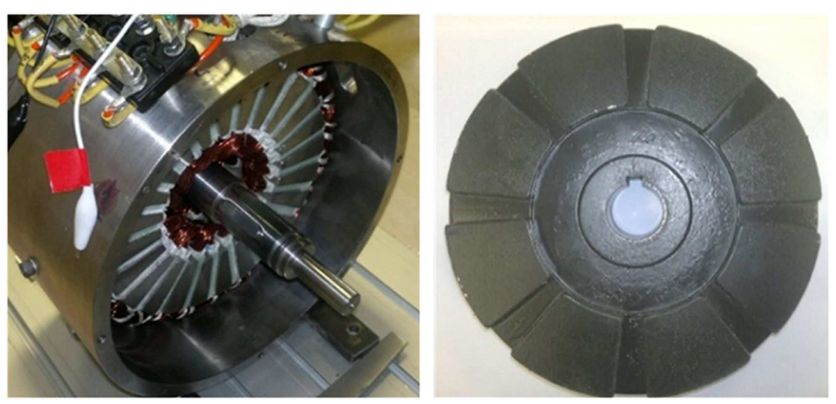

Fig. 6 Fan-shaped rotor structure of AFPM motor and its stator

IRMA and 2D ORMA motor models. Each 2D motor model, which could have inner, outer, or linear rotor, is then examined with several 2D FEA computations. Contributions from each approximated models and the superposition of them provide the actual output of the AFPM motor. The critical issue here is the number of cut-planes which determine the time and accuracy of the solution. Flux density profile of 3D and 2D modelling approaches are kept the same and given for a fan-shaped double rotor AFPM in Fig. 5 in order to clarify the modelling techniques.

\section{Investigated AFPM motors by 2D FEA modelling}

Three different AFPM motors are investigated in this study to validate proposed 2D modelling methods. A dual-rotor AFPM motor with fan- and triangular-shaped magnet rotors and a dual- rotor coreless AFPM motor are built and tested to validate the proposed approaches. Some important parameters of the investigated AFPM motors are given in the Appendix. A set of parametric study is carried out for various AFPM motors to obtain the optimum number of $2 \mathrm{D}$ segments. Results of the parametric study are given in the Appendix.

\subsection{Two-dimensional FEA modelling of a dual-rotor AFPM motor with fan-shaped rotor magnets}

Previously built AFPM motor, fan-shaped magnets and rotor disc are shown in Fig. 6. AFPM motor with fan-shaped magnets is modelled with three 2D segments (or two cut planes) after a series of parametric study (see the Appendix). The models are then approximated to 2D linear segments and a series of FEA simulations are carried out. Three approximated linear FEA models are used here because three models are adequate to attain correct results. However, the number of segments can be increased to get more accurate output torque and back-EMF.

Back-EMF waveforms of the AFPM motor with fan-shaped magnets at $100 \mathrm{rpm}$ obtained from 3D FEA, 2D LMMA, 2D IRMA, 2D ORMA, and experimental results are given in Fig. $7 a$. Back-EMF waveform of the motor is tested and verified with 3D FEA. As seen in the figure, all 2D modelling approaches are in good agreement with experiment results. Harmonic contents of the approaches are also presented in Fig. 7b. It can be concluded that all $2 \mathrm{D}$ modelling approaches are close to actual back-EMF profile with some error.

Cogging torque and torque output simulations are also carried out with all 2D approaches and results are provided in Figs. $7 c$ and $d$, respectively. Results obtained from $2 \mathrm{D}$ modelling techniques are compared with 3D FEA and experimental data and results are summarised in Tables 1 and 2, respectively.

The peak cogging torque of $8 \mathrm{~N} \mathrm{~m}$ is experimentally measured and validated with 3D FEA result. Results, given in Table 1, obtained from 2D modelling approaches are in good agreement with the test results in terms of the shape of the waveform and the peak value. FEA modelling with 2D ORMA introduces some error on peak value due to more flux leakage components.

Average torque output and torque ripple are provided in Table 2. A $38.2 \mathrm{~N} \mathrm{~m}$ average torque output with $35.8 \%$ ripple is obtained with 3D FEA. It is shown that results obtained from all 2D modelling approaches have nearly same average torque. However, significant error is introduced by 2D ORMA due to simplifications in magnet pole-arc. It can be concluded that $2 \mathrm{D}$ FEA modelling approaches with 2D LMMA and 2D IRMA can be used to predict torque output as well as torque ripple with small errors. Table 3 summarises the comparison of motor performance data and computation time among all FEA modelling approach including 3D FEA. It is concluded that 2D modelling approaches work well for AFPM motors. It can be observed that LMMA and IRMA provide the best results among the 2D FEA modelling approaches. 

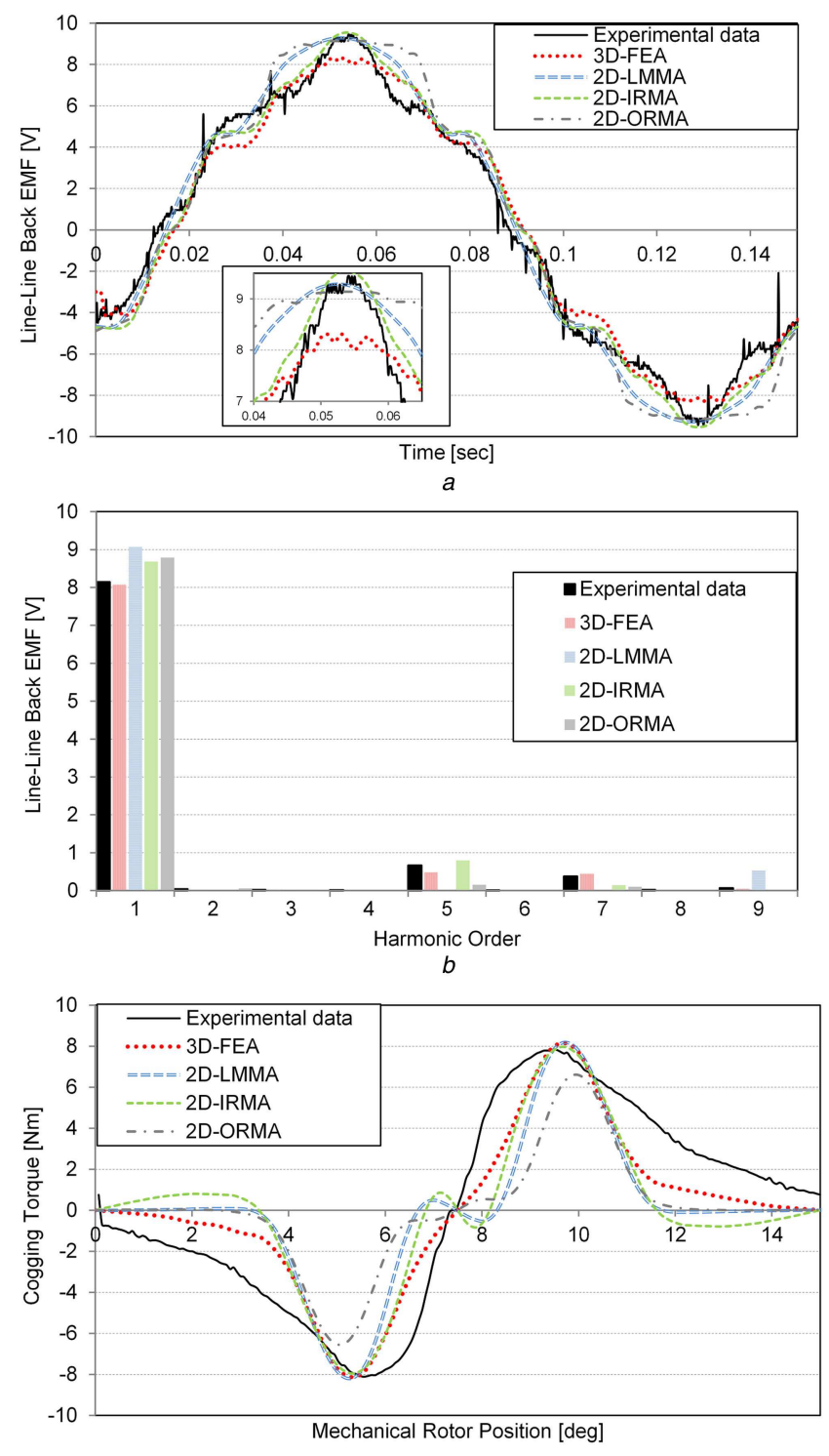

$c$

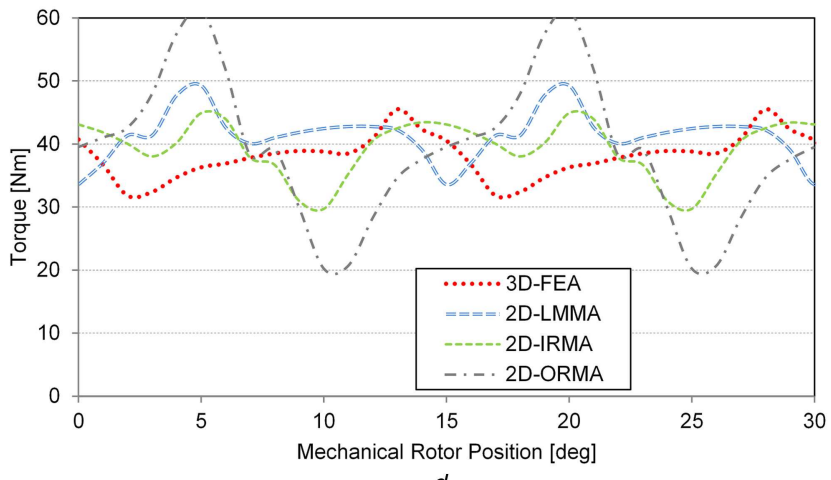

d

Fig. 7 Comparison of

(a) Back-EMF waveforms at $100 \mathrm{rpm}$, (b) Harmonic contents for AFPM motor with fan-shaped magnets, (c) Cogging torque profile for fan-shaped AFPM motor, (d) Torque output for fan-shaped AFPM motor

Table 1 Peak cogging torque comparison for AFPM motor with fan-shaped magnets

\begin{tabular}{lcc}
\hline Cases & Peak cogging torque, $\mathrm{N} \mathrm{m}$ & Error, $\%$ \\
\hline experimental data & 8.0 & - \\
3D FEA & 7.95 & 0.6 \\
2D LMMA & 8.04 & -0.5 \\
2D IRMA & 7.46 & 6.7 \\
2D ORMA & 6.60 & 17.5 \\
\hline
\end{tabular}

4.2 Two-dimensional FEA modelling of dual-rotor AFPM motor with triangular-shaped rotor magnets

A previously built and tested eight-pole dual-rotor AFPM motor with triangular-shaped magnets, given in Fig. 8, is modelled with 12 linear segments after a series of parametric studies (see the Appendix for details). Owing to non-central symmetrical magnet shape, large number of linear segments are required to obtain more accurate results.

Comparison of back-EMF waveforms of the AFPM motor with triangular-shaped magnets at $100 \mathrm{rpm}$ is given in Fig. $9 a$. BackEMF waveform is experimentally verified and it is shown that all 2D modelling approaches work well with experiment results. Harmonic contents are also simulated and compared as given in Fig. $9 b$. It can be concluded that all 2D modelling approaches are in good agreement with the back-EMF profile and harmonic contents. Especially, harmonics contents of 2D IRMA are well fitted with experiments.

Cogging and output torque profiles are also simulated by $2 \mathrm{D}$ FEA with different approaches and the results are displayed in Figs. $9 c$ and $d$, respectively. Comparison of results obtained from 2D modelling approaches as well as 3D FEA and experimental data are provided in Tables 4 and 5. The peak cogging torque value of $2.68 \mathrm{~N} \mathrm{~m}$ is experimentally measured for the triangular-shaped magnet AFPM motor. Results obtained from 2D FEA modelling approaches are in good agreement. Cogging torque profiles including 3D FEA results match well with the experimental cogging data in terms of the waveform shape and the peak value.

Torque output waveform and torque ripple values are also given in Table 5. Average torque output can be estimated within $\sim 2 \%$ error using all 2D modelling approaches due to high number of segments used in modelling. However, it is obvious that all approaches do not work well in estimating torque ripple due to several assumptions. Comparison of all 2D FEA modelling approaches is shown in Table 6. It is concluded that 2D LMMA and 2D IRMA work appropriately for triangular-shaped AFPM motor analyses.

\subsection{Two-dimensional FEA modelling of coreless dual-rotor AFPM disc motor}

Another AFPM motor modelled with the proposed approach is a 24-pole coreless dual-rotor AFPM motor, which is designed for an in-wheel traction motor given in Fig. 10. It is modelled with only one $2 \mathrm{D}$ segment (see parametric study in the Appendix) since there is no stator-core component, which complicates modelling and adds non-linearity to the problem. Owing to coreless structure and somewhat linear magnetic system, previously designed and built AFPM motor can be modelled with any of the $2 \mathrm{D}$ modelling approaches.

Back-EMF waveform comparison and harmonic contents of the coreless AFPM motor at $400 \mathrm{rpm}$ are given in Fig. 11. First, backEMF waveform obtained by 3D FEA is verified experimentally. All 2D modelling approaches are utilised with one 2D segment and it is seen that the results agree with experiment data. In addition, harmonic contents are also in excellent agreement with the test results simply because of the air-gap winding or large electrical airgap.

Torque output profile is also examined using all 2D FEA modelling approaches and the results are provided in Fig. 11 c and Table 7. The obtained results are compared with 3D FEA and experimental data as well. It is seen that the average torque components can be estimated within roughly $3.3 \%$. Unlike other cored motors, torque ripple can also be estimated well with all 2D modelling techniques. It is clearly shown that all 2D FEA modelling techniques work extremely well for the coreless AFPM motors.

\section{Comparison of 3D FEA and 2D FEA modelling based on computational time}

Computational time of all 2D/3D FEA simulations for AFPM motors are also explored. Mesh profiles and simulation time of studied cases are given for the first cored AFPM motor in Fig. 12 
Table 2 Torque output comparison for AFPM motor with fan-shaped magnets

\begin{tabular}{lcc}
\hline Cases & Ave. torque, $\mathrm{N} \mathrm{m}$ & Torque ripple, $\%$ \\
\hline 3D FEA & 38.2 & 35.8 \\
2D LMMA & 41.69 & 37.68 \\
2D IRMA & 39.49 & 38.38 \\
2D ORMA & 39.34 & 103.99 \\
\hline
\end{tabular}

Table 3 Comparison of FEA modelling for AFPM motor with fan-shaped magnets

\begin{tabular}{lcccc}
\hline Cases & $\begin{array}{c}\text { Cogging } \\
\text { torque }\end{array}$ & $\begin{array}{c}\text { Torque } \\
\text { output }\end{array}$ & $\begin{array}{c}\text { Back- } \\
\text { EMF }\end{array}$ & $\begin{array}{c}\text { Computation } \\
\text { time }\end{array}$ \\
\hline 3D FEA & $\checkmark \checkmark \checkmark$ & $\checkmark \checkmark \checkmark$ & $\checkmark \checkmark \checkmark$ & $\checkmark$ \\
2D LMMA & $\checkmark \checkmark \checkmark$ & $\checkmark \checkmark$ & $\checkmark \checkmark \checkmark$ & $\checkmark \checkmark \checkmark$ \\
2D IRMA & $\checkmark \checkmark \checkmark$ & $\checkmark \checkmark$ & $\checkmark \checkmark \checkmark$ & $\checkmark \checkmark \checkmark$ \\
2D ORMA & $\checkmark$ & $\checkmark$ & $\checkmark \checkmark \checkmark$ & $\checkmark \checkmark \checkmark$ \\
\hline
\end{tabular}
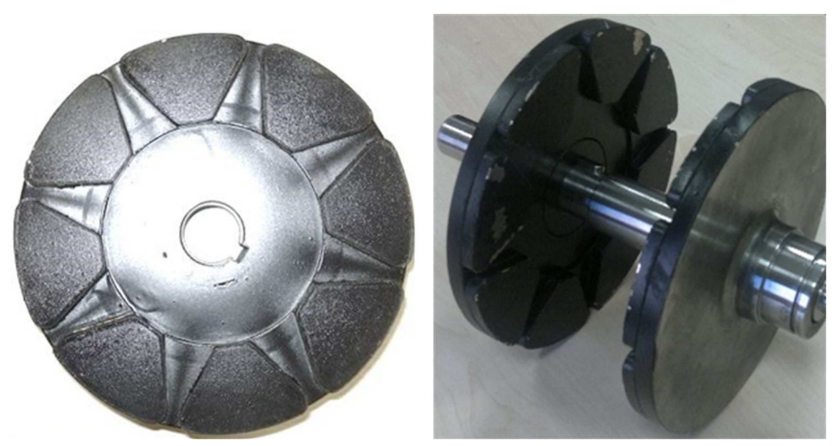

Fig. 8 Triangular-shaped rotor structure of AFPM motor used in simulations

Table 4 Peak cogging torque comparison for AFPM motor with triangular-shaped magnets

\begin{tabular}{lcc}
\hline Cases & Peak cogging torque, $\mathrm{N} \mathrm{m}$ & Error, \% \\
\hline experimental data & 2.68 & - \\
3D FEA & 2.52 & 6.0 \\
2D LMMA & 2.80 & -4.4 \\
2D IRMA & 2.36 & 11.9 \\
2D ORMA & 2.54 & 5.2 \\
\hline
\end{tabular}

Table 5 Torque output comparison for AFPM motor with triangular-shaped magnets

\begin{tabular}{lcc}
\hline Cases & Ave. torque, $\mathrm{N} \mathrm{m}$ & Torque ripple, $\%$ \\
\hline 3D FEA & 36.33 & 5 \\
2D LMMA & 35.26 & 12.15 \\
2D IRMA & 37.08 & 13 \\
2D ORMA & 36.59 & 24.87 \\
\hline
\end{tabular}

Table 6 Comparison of FEA modelling approaches for AFPM motor with triangular-shaped magnets

\begin{tabular}{lcccc}
\hline Cases & $\begin{array}{c}\text { Cogging } \\
\text { torque }\end{array}$ & $\begin{array}{c}\text { Torque } \\
\text { output }\end{array}$ & $\begin{array}{c}\text { Back- } \\
\text { EMF }\end{array}$ & $\begin{array}{c}\text { Computation } \\
\text { time }\end{array}$ \\
\hline 3D FEA & $\checkmark \checkmark \checkmark$ & $\checkmark \checkmark \checkmark$ & $\checkmark \checkmark \checkmark$ & $\checkmark$ \\
2D LMMA & $\checkmark \checkmark$ & $\checkmark \checkmark$ & $\checkmark \checkmark \checkmark$ & $\checkmark \checkmark$ \\
2D IRMA & $\checkmark \checkmark \checkmark$ & $\checkmark \checkmark$ & $\checkmark \checkmark \checkmark$ & $\checkmark \checkmark$ \\
2D ORMA & $\checkmark \checkmark \checkmark$ & $\checkmark \checkmark$ & $\checkmark \checkmark \checkmark$ & $\checkmark \checkmark$ \\
\hline
\end{tabular}

as an example. Considerably less simulation time can be achieved with the proposed 2D modelling approaches due to simplicity and mesh structures. Three-dimensional and all the proposed 2D FE modelling have the same simulation step time and almost the same
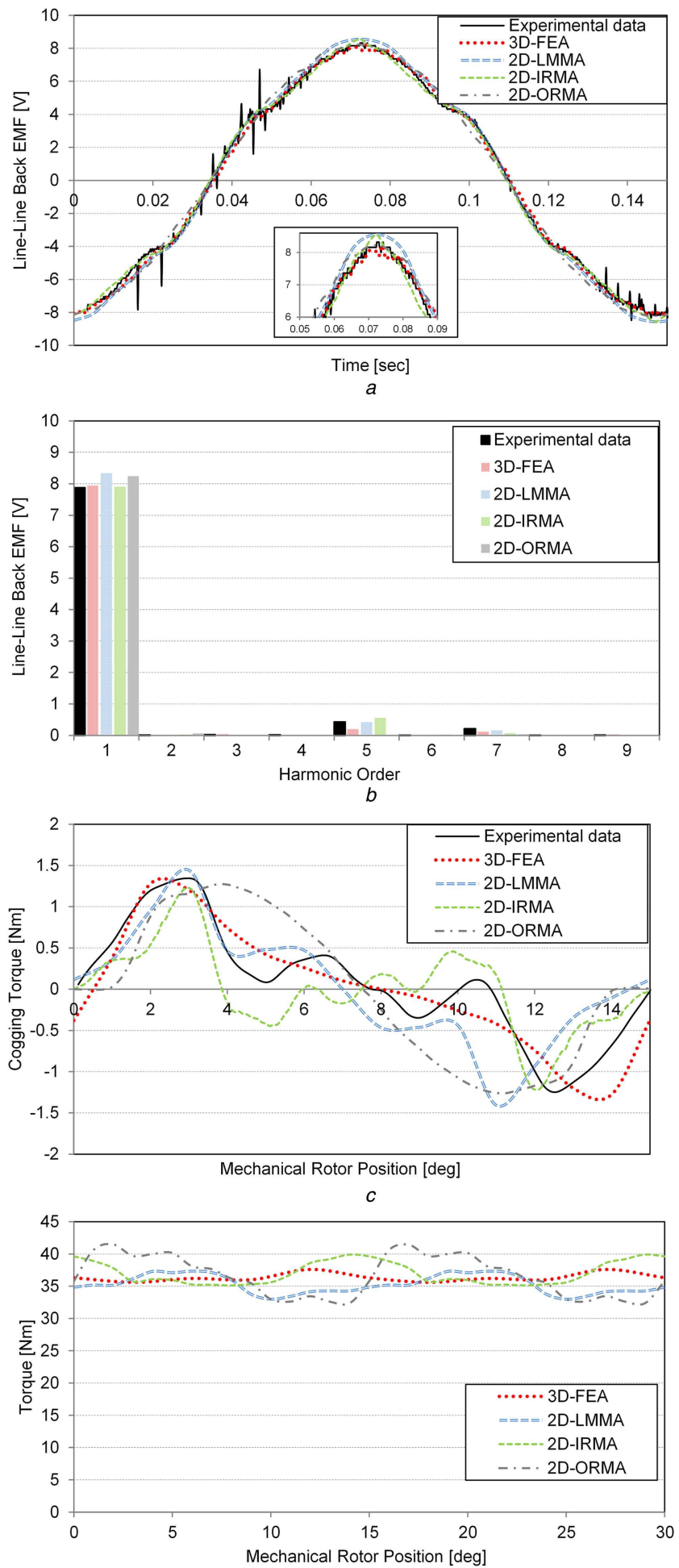

$d$

Fig. 9 Comparison of

(a) Back-EMF waveforms at $100 \mathrm{rpm}$, (b) Harmonic contents for AFPM motor with triangular-shaped magnets, (c) Cogging torque profiles for triangular-shaped AFPM motor, (d) Torque output profile for the AFPM motor with triangular-shaped magnets

mesh density levels during the $2 \mathrm{D}$ analyses. It is obtained that $3 \mathrm{D}$ FEA modelling has nearly 20 times more mesh elements compared with $2 \mathrm{D}$ models. Therefore, more simulation time is expected for the 3D FEA. As an example, for one period of cogging torque simulation in 3D FEA, 2D LMMA, 2D IRMA, and 2D ORMA take $2296,11,22.5$, and $16 \mathrm{~s}$, respectively. This proves that computation time can be reduced dramatically by 2D FEA modelling approaches with reasonable accuracy.

In addition, roughly up to 114 times fast computational time can be gained by the proposed 2D FEA modelling techniques. It can clearly be said that time-consuming analyses such as parametric 

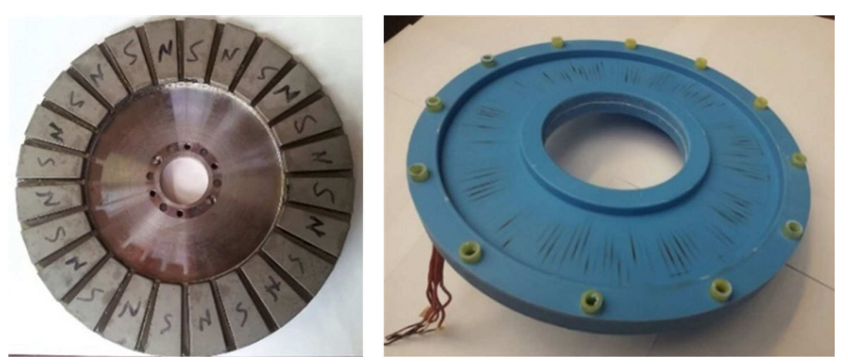

Fig. 10 Coreless double-rotor AFPM motor with 24 poles designed for in-wheel traction motor
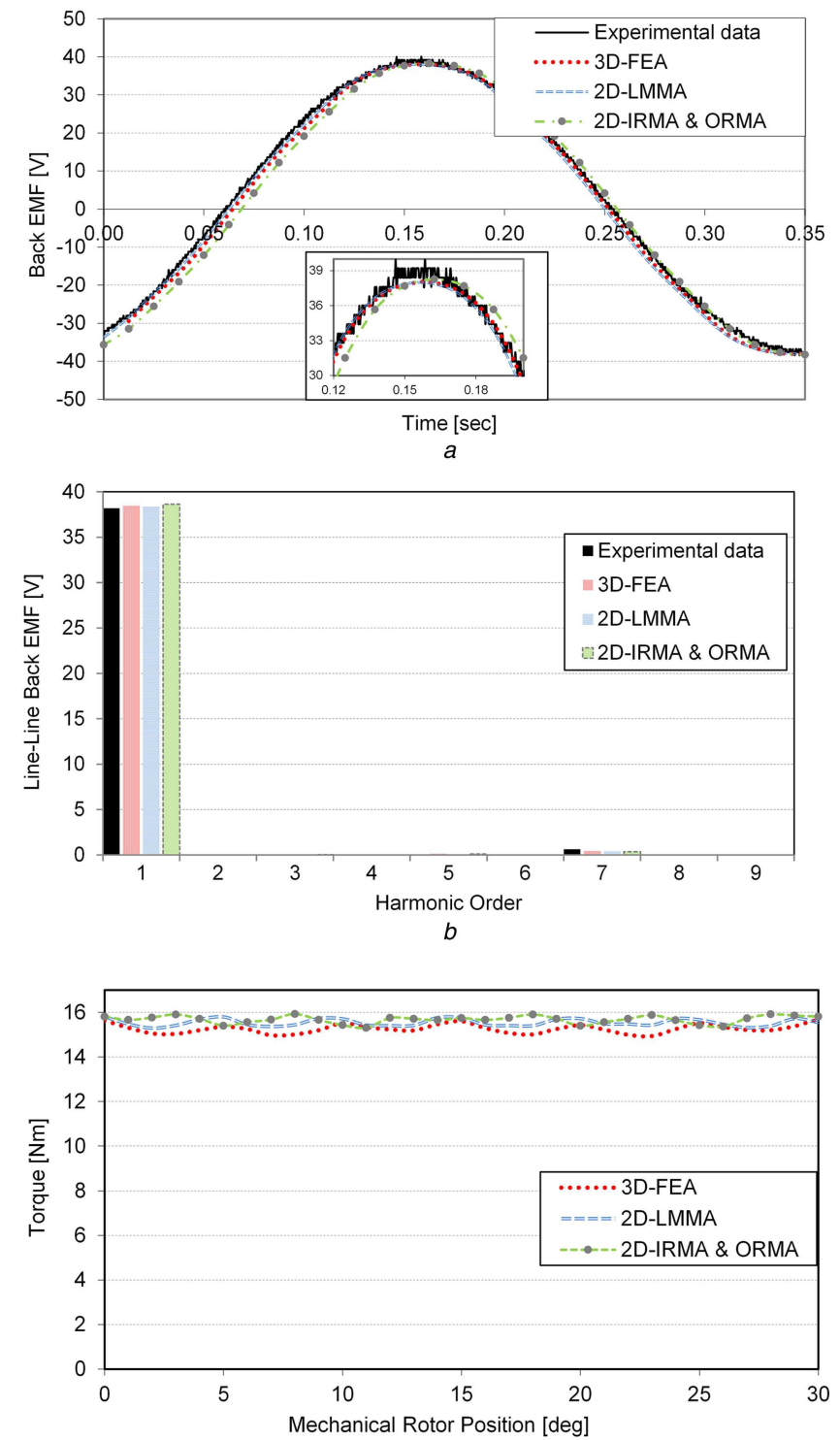

$c$

Fig. 11 Comparison of

(a) Back-EMF waveforms at $400 \mathrm{rpm}$, (b) Harmonic contents for coreless AFPM motor for 2D/3D FEA, (c) Torque output waveforms for coreless AFPM motor

Table 7 Torque output results for coreless AFPM motor

\begin{tabular}{lcc}
\hline Cases & Ave. torque, $\mathrm{N} \mathrm{m}$ & Torque ripple \% \\
\hline experimental data & 14.46 & $\mathrm{~N} / \mathrm{A}$ \\
3D FEA & 14.96 & 4.55 \\
2D LMMA & 15.04 & 3.33 \\
2D IRMA-ORMA & 15.16 & 3.95 \\
\hline
\end{tabular}

FEA can be carried out confidently by 2D FEA modelling approaches rather than 3D FEA for the AFPM motors.

\section{Conclusions}

In this paper, simple and accurate 2D finite element modelling approaches with inner and outer rotors for 3D AFPM motor problems are investigated for the first time in the literature. These approaches are applied to various AFPM motors in order to see how accurate the methods are on cogging torque, back-EMF, and average torque components. The $2 \mathrm{D}$ modelling approaches are based on dividing the 3D model into circumferential 2D segments. All studied approaches with optimum 2D segments are applied to a fan- and triangular-shaped magnet and a coreless AFPM motors. It is shown that the superposition of $2 \mathrm{D}$ models do provide close results to 3D FEA results and experimental data. In addition, the results show that AFPM motors can be modelled by the proposed 2D FE approaches and some of 2D modelling methods provide 


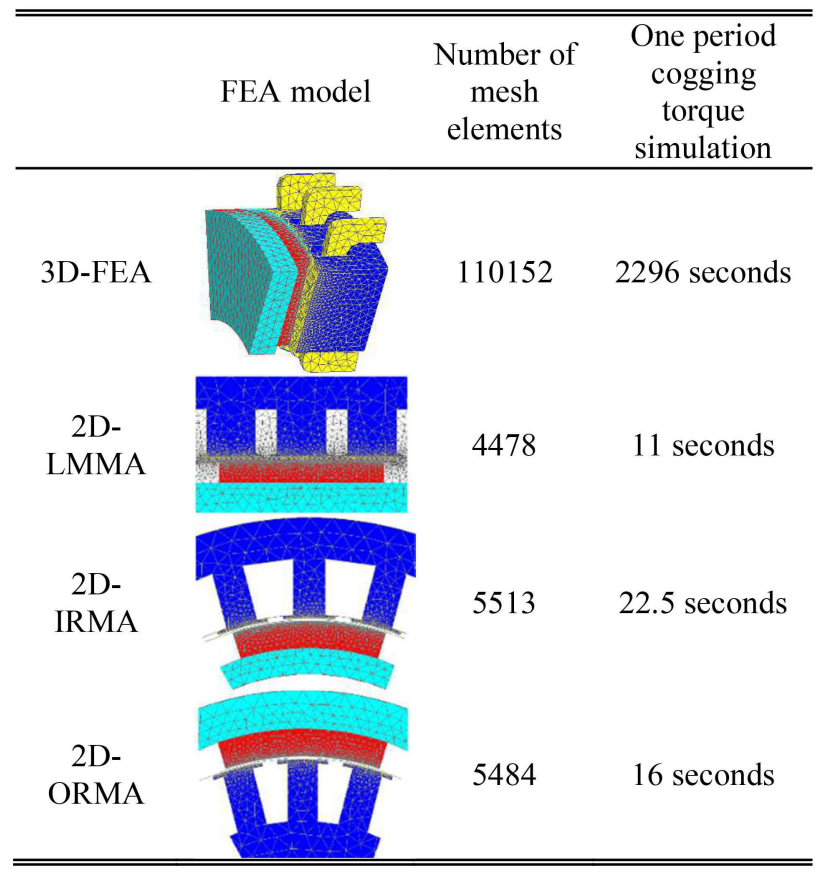

Fig. 12 Comparison based on mesh profile and computation time of FEA modellings (investigated AFPM motor case A)

Table 8 Suggested 2D FE modelling techniques for AFPM motors

\begin{tabular}{lcccc}
\hline & Fan-shaped & \multicolumn{2}{c}{ Triangular-shaped Coreless AFPM } \\
& AFPM motors & AFPM motors & motors \\
\hline 2D LMMA & $\checkmark$ & $\checkmark$ & $\checkmark$ \\
2D IRMA & $\checkmark$ & $\checkmark$ & $\checkmark$ \\
2D ORMA & $x$ & $x$ & $\checkmark$ \\
\hline
\end{tabular}

quite reasonable accuracy. Suggested 2D methods for AFPM motors are given in Table 8. Some important conclusions are provided as follows:

- Conventional dual-rotor AFPM motors, which have central symmetric magnet structure, can be modelled by 2D LMMA or 2D IRMA.

- Complex PM-shaped AFPM motors such as triangular-shaped or skewed magnets have non-central symmetric magnet structure and could be modelled by both 2D LMMA and 2D IRMA with more number of segments or 2D FEA models.

- Coreless AFPM motors can be modelled more easily and accurately than cored AFPM motors. They can be analysed with only a few 2D segments with any modelling approach because coreless structure eliminates most non-linearities simplifying the modelling.

- Higher number of poles in AFPM motors results in fewer number of 2D segments leading to less number of 2D FEA simulations with any 2D modelling approach.

- Both 2D IRMA and 2D ORMA have potentially faster modelling time as opposed to 2D LMMA thanks to commercial $2 \mathrm{D}$ templates. This generates an advantage if more number of 2D segments have to be used.

- No-load and on-load results could be directly obtained by 2D IRMA and 2D ORMA contrary to 2D LMMA. If high number of 2D segments were used, 2D IMRA and 2D ORMA would be the best options for on-load and no-load analyses.

- Optimum number of 2D segments can be found for the AFPM motor topology to reduce the 2D FEA computation time.

\section{Acknowledgment}

The authors are indebted to Altair for providing Flux 2D/3D FEA software.

\section{References}

[1] Cavagnino, M., Lazzari, F., Profumo, A.: 'A comparison between the axial flux and the radial flux structures for PM synchronous motors', IEEE Trans. Ind. Appl., 2002, 34, (6), pp. 1517-1524

[2] Sitapati, K., Krishnan, R.M.: 'Performance comparisons of radial and axial field, permanent-magnet, brushless machines', IEEE Trans. Ind. Appl., 2001, 37, (3), pp. 1219-1226

[3] Gieras, J.F., Wang, R., Kamper, M.J.: 'Axial flux permanent magnet brushless machines' (Kluwer, 2004)

[4] Chan, C.C.: 'Axial-field electrical machines-design and applications', IEEE Trans. Energy Convers., 1987, EC-2, (2), pp. 294-300

[5] Aydin, M., Huang, S., Lipo, T.A.: 'Torque quality and comparison of internal and external rotor axial flux surface-magnet disc machines', IEEE Trans. Ind. Electron., 2006, 53, (3), pp. 822-830

[6] Aydin, M., Zhu, Z.Q., Lipo, T.A. et al. 'Minimization of cogging torque in axial-flux permanent-magnet machines: design concepts', IEEE Trans. Magn., 2007, 43, (9), pp. 3614-3622

[7] Aydin, M., Guven, M.K.: 'Comparing various PM synchronous generators: a feasible solution for high-power, off-highway, series hybrid, electric traction applications', IEEE Trans. Veh. Technol., 2014, 9, (1), pp. 36-45

[8] Nguyen, T.D., Tseng, K.J., Zhang, S., et al.: 'A novel axial flux permanentmagnet machine for flywheel energy storage system: design and analysis', IEEE Trans. Ind. Electron., 2011, 58, (9), pp. 3784-3794

[9] Donato, G.D., Capponi, F.G., Caricchi, F.: 'No-load performance of axial flux permanent magnet machines mounting magnetic wedges', IEEE Trans. Ind. Electron., 2012, 59, (10), pp. 3768-3779

[10] Donato, G.D., Capponi, F.G., F.Caricchi, F.: 'On the use of magnetic wedges in axial flux permanent magnet machines', IEEE Trans. Ind. Electron., 2013 60, (11), pp. 4831-4840

[11] Hill-Cottingham, R.J., Coles, P.C., Rodger Lai, D.: 'Finite element modelling of an axial flux PM machine'. Proc. Int. Conf. on Power Electronics, Machines and Drives, Edinburg, UK, April 2004, pp. 552-555

[12] Vansompel, H., Sergeant, P., Dupré, L.: 'Optimized design considering the mass influence of an axial flux permanent-magnet synchronous generator with concentrated pole windings', IEEE Trans. Magn., 2010, 46, (12), pp. 4101-4107

[13] Tiegna, H., Bellara, A., Amara, Y., et al.: 'Analytical modeling of the opencircuit magnetic field in axial flux permanent-magnet machines with semiclosed slots', IEEE Trans. Magn., 2012, 48, (3), pp. 1212-1226

[14] Zhang, Z., Profumo, F., Tenconi, A., et al.: 'Analysis and experimental validation of performance for an axial flux permanent magnet brushless DC motor with powder iron metallurgy cores', IEEE Trans. Magn., 1997, 33, (5), pp. 4194-4196

[15] Egea, A., Almandoz, G., Poza, J., et al.: 'Axial-flux-machine modeling with the combination of FEM-2-D and analytical tools', IEEE Trans. Ind. Appl., 2012, 48, (4), pp. 1318-1326

[16] Maloberti, O., Figueredo, R., Marchand, C., et al.: '3-D-2-D dynamic magnetic modeling of an axial flux permanent magnet motor with soft magnetic composites for hybrid electric vehicles', IEEE Trans. Magn., 2014, 50, (6), Article Sequence Number: 8201511

[17] Zhao, F., Lipo, T.A., Kwon, B.: 'A novel dual-stator axial-flux spoke-type permanent magnet vernier machine for direct-drive applications', IEEE Trans. Magn., 2014, 50, (11), Article Sequence Number: 8104304

[18] Seo, J.M., Ro, J., Rhyu, S., et al.: 'Novel hybrid radial and axial flux permanent-magnet machine using integrated windings for high-power density', IEEE Trans. Magn., 2015, 51, (3), Article Sequence Number: 8100804

[19] Hekmati, P., Yazdanpanah, R., Mirsalim, M.: 'Design and analysis of doublesided slotless axial-flux permanent magnet machines with conventional and new stator core', IET Electr. Power Appl., 2015, 9, (3), pp. 193-202

[20] Hao, L., Lin, M., Xu, D., et al.: 'Cogging torque reduction of axial-field fluxswitching permanent magnet machine by rotor tooth notching', IEEE Trans. Magn., 2015, 51, (11), Article Sequence Number: 8208304

[21] Parviainen, A., Niemela, M., Pyrhonen, J.: 'Modeling axial-flux permanentmagnet machines', IEEE Trans. Ind. Appl., 2004, 40, (5), pp. 1333-1340

\section{Appendix}

See Fig. 13 and Table 9. 


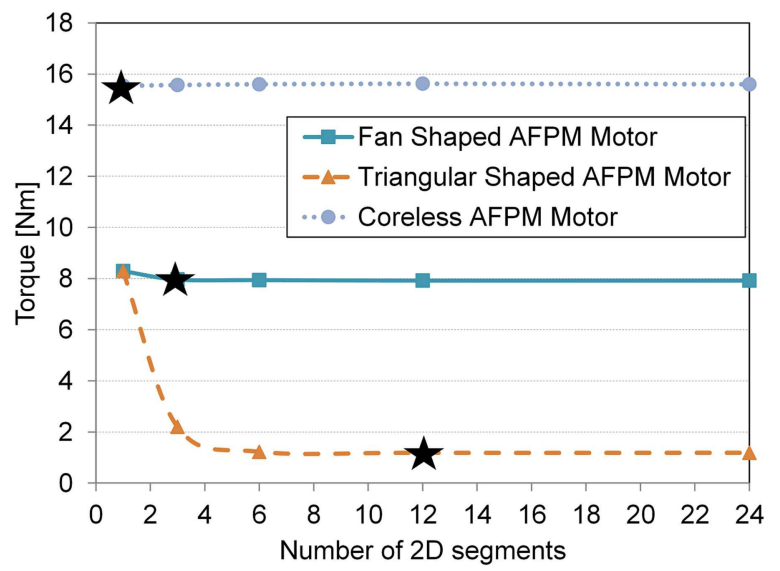

Fig. 13 Variation of output parameters of various AFPM motors for different $2 D$ segment numbers

Table 9 Some important parameters of investigated AFPM motors

\begin{tabular}{lcccc}
\hline & $T_{\text {avrg. }}, \mathrm{N} \mathrm{m}$ & $\lambda$ & $D_{\circ}$ & $L_{\mathrm{e}}, \mathrm{mm}$ \\
\hline fan-shaped AFPM motor & 38 & 0.56 & 180 & 45 \\
triangular-shaped AFPM motor & 36 & 0.56 & 180 & 45 \\
coreless AFPM motor & 15 & 0.6 & 268 & 37 \\
\hline
\end{tabular}

